\title{
Gestão social no terceiro setor e seus efeitos no desenvolvimento humano: um estudo de caso em uma Organização da Sociedade Civil (OSC) que atua no Estado do Rio
}

\section{Grande do Sul/Brasil}

\author{
Social management in the third sector and its effects on human development: a case study in a Civil \\ Society Organization (CSO) that operates in the state of Rio Grande do Sul / Brazil \\ La gestión social en el tercer sector y sus efectos en el desarrollo humano: un estudio de caso en una \\ Organización de la Sociedad Civil (OSC) que opera en el estado de Rio Grande do Sul / Brasil
}

Recebido: 12/01/2021 | Revisado: 14/01/2021 | Aceito: 21/01/2021 | Publicado: 22/01/2021

Taciana Angélica Moraes Ribas ORCID: https://orcid.org/0000-0002-7255-3793 Universidade Regional do Noroeste do Estado do Rio Grande do Sul, Brasil E-mail: taciana.ribas@sou.unijui.edu.br

Josiane Dilor Brugnera Ghidorsi

ORCID: https://orcid.org/0000-0003-4959-9272 Universidade Regional do Noroeste do Estado do Rio Grande do Sul, Brasil E-mail: josibrugnera@yahoo.com.br

Sérgio Luís Allebrandt

ORCID: https://orcid.org/0000-0002-2590-6226 Universidade Regional do Noroeste do Estado do Rio Grande do Sul, Brasil E-mail: allebr@unijui.edu.br

Romualdo Kohler

ORCID: https://orcid.org/0000-0003-2083-9279 Universidade Regional do Noroeste do Estado do Rio Grande do Sul, Brasil E-mail: romualdo@unijui.edu.br

Kátia Michele Maroski

ORCID: https://orcid.org/0000-0001-9041-2591 Universidade Regional do Noroeste do Estado do Rio Grande do Sul, Brasil E-mail: katiamichelem@yahoo.com.br

\begin{abstract}
Resumo
Este artigo está ancorado no estudo de caso, e busca analisar os impactos no desenvolvimento humano, promovido por uma Organização da Sociedade Civil - OSC, que atua apoiando pessoas que estão em tratamento oncológico no Estado do Rio Grande do Sul, bem como, traz discorre sobre as adaptações que foram necessárias para dar continuidade aos atendimentos em função da Covid-19. Sabe-se que o Terceiro Setor hoje vem para preencher lacunas deixadas pelos governos, uma vez que os mesmos não conseguem resolver todos os problemas sociais. Deste modo, é necessário que ações voluntárias, por meios das OSCs, ou de outros segmentos do terceiro setor, somem esforços para resultados transformadores na vida das pessoas, garantindo assim, que os sujeitos possam ter acesso a direitos, colocando-os em um patamar de inclusão e empoderamento. Quanto aos procedimentos metodológicos, este trabalho está orientado pelas pesquisas sociais aplicadas e se classifica como uma pesquisa interpretativa participante, de natureza qualitativa, explicativa e descritiva, em que se acompanhou por cerca de dois anos e meio o dia a dia da OSC. O estudo constatou a importância desta entidade na vida das pessoas, uma vez que se percebeu o quanto este apoio foi positivo para estas famílias assistidas fortalecendo-os e proporcionando acalento frente ao tratamento oncológico.
\end{abstract}

Palavras-chave: Organização da sociedade civil; Gestão social; Terceiro setor; Desenvolvimento humano; Covid-19.

\begin{abstract}
This article is based in a study of case that craves to analyze which are the impacts in human development, promoted by an Organization of Civil Society - OCS that acts supporting people who are in oncologic treatment in the State of Rio Grande do Sul, as well as, expatiates about the adaptions that were needed to give continuity to the services in Covid-19's function. It is known that nowadays the Tertiary Sector appears as an option to fill the blanks that the governments leave behind, once that they cannot solve all the social issues. Thus, it is necessary, that voluntary actions, through the OCSs or through other cantles of the tertiary sector sum efforts to make a transformative result in people's life, ensuring this way, that the people can have access to their rights, putting them in an inclusion space and
\end{abstract}


empowerment, specially about health questions. About the methodologic process, this research was constructed from qualitative nature, explanatory and descriptive, where it was accompanied for about two and a half years the daily life inside the OCS. The study found the importance of this entity in people's life, once it was noticed how much this support was positive for these families assisted, making them stronger and providing cherish facing the oncologic treatment.

Keywords: Civil society organization; Social management; Third sector; Human development; Covid- 19.

\section{Resumen}

Este artículo está apoyado en el estudio de caso, y busca analizar los impactos en el desenvolvimiento humano, promovido por una Organización de la Sociedad Civil - OSC, que actúa apoyando personas que están en tratamiento oncológico en el Estado de el Rio Grande do Sul, así como, explaya cerca de las adaptaciones que fueran necesarias para que hubiese continuidad a los atendimientos en función de el Covid-19. Se sabe que el Tercer Sector actualmente viene para llenar espacios dejados por los gobiernos, una vez que los mismos no pueden resolver todos los problemas sociales. De este modo, es necesario que acciones voluntarias, por medios de las OSCs, o de otros segmentos de el Tercer Sector, suman fuerzas para resultados transformadores en la vida de las personas, garantiendo así, que los sujetos puedan tener acceso a directos, os colocando en un nivel de inclusión y empoderamiento. Cuanto a los procedimientos metodológicos, este trabajo está orientado por las pesquisas sociales aplicadas y es clasificado como una pesquisa interpretativa participante, de naturaleza cualitativa y descriptiva, en que fue acompañado por cerca de dos años y medio el cotidiano de la OSC. El estudio constató la importancia de esta entidad en la vida de las personas, una vez que se percibió cuanto este apoyo fue positivo para estas familias soportadas, os fortaleciendo e proporcionando calidez frente a el tratamiento oncológico.

Palabras clave: Organización de la sociedad civil; Gestión social; Tercer sector; Desarrollo humano; Covid- 19.

\section{Introdução}

Tem se notado nos últimos anos, a ampliação da ação de instituições inseridas na área do Terceiro Setor, as quais buscam atender demandas sociais não atendidas pelo Estado. No limiar da história, constata-se que as organizações do terceiro setor surgiram inicialmente em 1601 na Inglaterra, institucionalizada pela Rainha Elizabeth I, em um decreto que foi chamado de "Estatuto dos Usos Caritativos", que objetivou o combate à pobreza por meio de recursos captados pela Coroa, advindos sobretudo, dos impostos cobrados (Levitt, 1973).

No Brasil, desde meados dos anos 70, tem se percebido a institucionalização do terceiro setor - organizações da sociedade civil, sem fins lucrativos (Tenório, 2008), as quais foram expandidas nos anos 80; sendo que somente nos últimos anos tem se compreendido a importância deste seguimento, que nasceu para atuar como uma extensão da ação do Estado, cobrindo lacunas de participação social (Costa \& Rosa, 2003).

O terceiro setor é um "conjunto de organizações e iniciativas privadas que visam à produção de bens e serviços públicos, que nesse caso implicam uma dupla qualificação: não geram lucros e respondem às necessidades coletivas (1994, p. 21) ". São instituições que surgiram e são mantidas por ações e participação voluntárias, as quais buscam dar andamento às práticas tradicionais de caridade, da filantropia (Fernandes, 1997).

Estas OSCs - Organizações da Sociedade Civil apresentam uma capacidade para trabalhar com as demandas sociais de forma consistente, ampliando cada vez mais seus serviços, e apoiadores, como voluntários e empreendedores sociais, que compreendem a real necessidade e importância do terceiro setor.

Este seguimento é percebido por muitos de forma positiva e otimista, pois como já enfatizando por outros autores, estas organizações, além de atuarem sem prever lucros, ainda tem a habilidade de assegurar a participação da sociedade, trabalhando no vácuo, deixado pelo setor público (Costa \& Rosa, 2003).

Tenório (2008. p. 90), conclui que:

O processo de institucionalização do terceiro setor é que a sua legitimação tem sido aferida pelo desempenho do setor como um dos enclaves centrais e emergentes da sociedade contemporânea. E esse desempenho é observado em diferentes contextos culturais, socioeconômicos e políticos. Sociedades ricas e pobres têm utilizado o terceiro setor ora para catalisar anseios de determinados segmentos da população, ora para atender necessidades da sociedade como 
um todo. Em alguns casos, agentes deste setor assumem um papel fundamental na conquista de justiça social nas vezes em que nem o Estado nem os agentes econômicos têm interesse ou são capazes de promovê-la.

Atualmente no Brasil, estão constituídas cerca de setecentas e oitenta mil ONGs/OSCs, como podemos ver a evolução no Gráfico 1, as quais empregam aproximadamente dois milhões e duzentas mil pessoas, sendo que deste número, mais de um milhão e trezentas mil pessoas estão na região Sudeste (IPEA, 2018).

Gráfico 1. Evolução da quantidade de OSCs no Brasil (2010 - 2018).

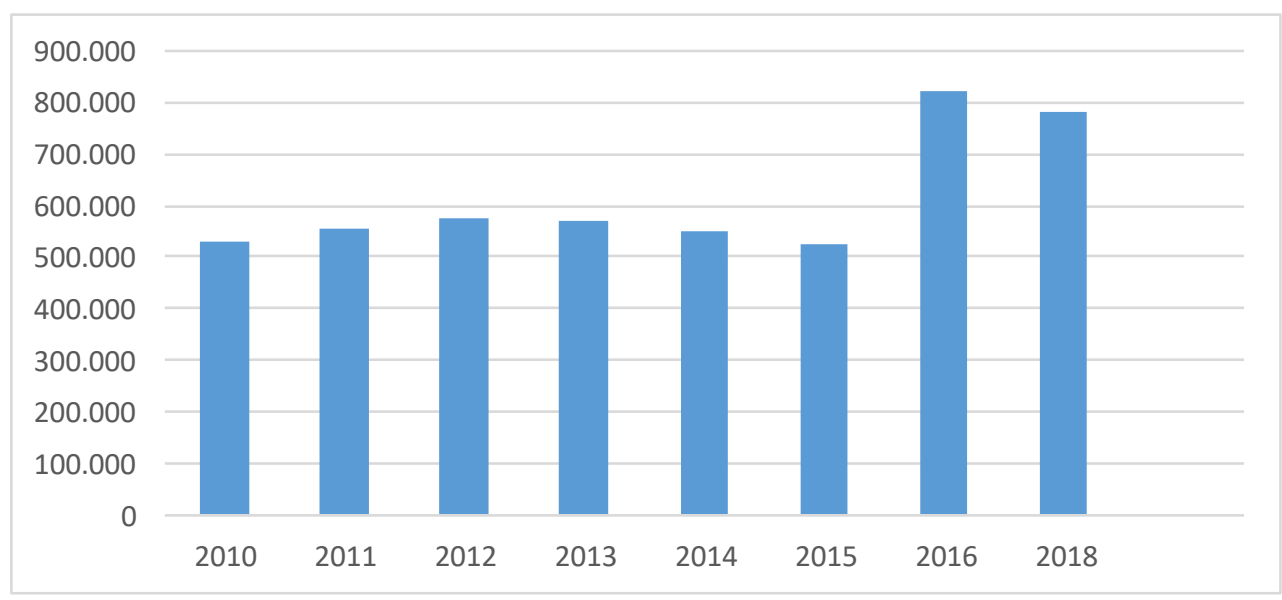

Fonte: adaptado de Ribas et al., (2020).

As áreas são diversas: assistência social, educação, saúde, esportes e lazer, meio ambiente, geração de emprego e renda, artes e cultura, ciência e tecnologia, comunicação, segurança pública etc. O que chama mais a atenção, é que as que atendem na defesa e garantia dos direitos humanos e em projetos de desenvolvimento social, são as que mais se destacaram e aumentaram.

Para que estas instituições sem fins lucrativos do Terceiro Setor, as ONGs/OSCs, tenham sucesso nas suas atribuições, se entende que estas necessitam ter uma boa gestão para o seu progresso no mercado e sustentabilidade (Santos et al, 2019).

Neste caminho, se constata que estas instituições estão planejando e se profissionalizando cada vez mais, para que possam estar aptos a realizarem os trabalhos a que se propõem, capacitando as pessoas envolvidas - funcionários e voluntários. Isto é fundamental, já que enfrentam muitos desafios, e o mais notório é a captação de recursos, vital para a sobrevivência de uma OSC (Ribas et al, 2020).

A captação de recursos pode ser classificada como sendo a tarefa mais complexa, pois há todo um trabalho de conscientizar e sensibilizar potenciais doadores, que se identifiquem ou que venham a se identificar com a causa trabalhada, contribuindo assim com apoio ao público beneficiário (Ribas et al, 2020). "Estas OSCs acabam sendo interlocutoras entre as pessoas que querem fazer sua doação/contribuição a uma causa social, para as que necessitam deste apoio, fazendo com que, a solidariedade chegue até elas (Ribas et al, 2020, p.14)".

As OSCs estão atuando fortemente na área de marketing e gestão que possam vir melhorar o desempenho de suas atividades, constituindo-se assim, em organizações estruturadas, por meio das técnicas de comunicação, gestão organizacional e de recursos humanos, colocando-as em um patamar mais eficiente no operacional de suas tarefas-fim, pois os envolvidos possuem largas experiências nas questões sociais.

Estas organizações/instituições possuem uma alta capacidade de mobilização, em que acabam estabelecendo relações com outras OSCs, por meio de parcerias para que possam desenvolver melhor suas tarefas, pois a troca de experiências/conhecimentos e o aperfeiçoamento de suas ações por meio da rede de relações proporciona a ampliação do 
atendimento, aumentado assim à quantidade de beneficiários, estruturando-se em uma ampla cadeia de técnicas, processos e métodos de gestão social.

É na gestão social, que Tenório (1998) enfatiza que devem estar embasados os caminhos do Terceiros Setor, uma vez que o sujeito (a pessoa beneficiada) não pode ser visto como consumidor ou um cliente, e sim na perspectiva do cidadão, em sua emancipação como pessoa. Enfatiza ainda que:

O terceiro setor tem seu enfoque assentado no fato de os "sistemas-governo, com suas perspectivas de Estado mínimo, assim como os sistemas-empresa, estabelecendo estratégias de ação social, ora propõem parcerias ora deixam por conta do terceiro setor a responsabilidade para atender as deficiências sociais" (Tenório, 1998. p.19), historicamente não atendidas pelo primeiro e segundo setores.

Para Cabral (2007) o Terceiro Setor é um espaço em que lógicas diversas, discursos e racionalidades, advindas do Estado, setor mercantil e da comunidade, são correlacionadas por um objetivo comum de proteção e desenvolvimento sociais.

Ainda sugere que o Terceiro Setor (TS) é um

Espaço no qual se realizam estas sociabilidades como um espaço público equipado de atributos que Cabral (2007) identificou nos valores: representação de interesses coletivos; democratização; qualidade; efetividade: visibilidade; cultura pública; universalidade; autonomia; controle e defesa social; e sustentabilidade, propostos por Wanderley (1998, apud Cabral, 2008. p. 6) no seu estudo das instituições educacionais comunitárias. Esta estrutura de valores impõe que a gestão social seja a gestão que produza os bens públicos e reproduza os valores sociais que permitam o florescimento deste espaço articulado pelo TS.

É por meio da Gestão Social no Terceiro Setor, que são firmados espaços que se é possível acessar diversas fontes de recursos sociais - fundos públicos, trabalho voluntário, doações privadas de pessoas e empresas, entre outras (Cabral, 2007).

Os trabalhos realizados pelas OSCs ajudam o indivíduo no desenvolvimento humano (DH), que na ótica do Programa das Nações Unidas para o Desenvolvimento (PNUD), o sujeito é moldado de acordo com as oportunidades que tem ao longo de sua trajetória, o que acarretará em suas escolhas e capacidades. DH é o processo de ampliação das liberdades das pessoas, garantindo-lhes seus direitos como cidadãos, e centra-se na ampliação do seu bem-estar (PNUD, 2000).

Assim, se percebe elementos da Gestão Social, no escopo que orienta o Terceiro Setor, desta forma, este estudo estará trabalhando o Terceiro Setor, a luz da Gestão Social, para analisar o comportamento e a importância que as OSCs têm na vida das pessoas na atualidade.

Este artigo, além desta introdução, traz uma breve abordagem sobre o referencial teórico - gestão social, terceiro setor e desenvolvimento humano; os procedimentos metodológicos; apresentação e análise da Osc estudada; resultados e discussões; considerações finais, finalizando com as referências bibliográficas.

\section{Metodologia}

Este estudo se enquadra nas pesquisas sociais aplicadas, pois está apoiada no propósito pela simples satisfação para agir (Gil, 2008) e "procura desenvolver os conhecimentos científicos sem a preocupação direta com suas aplicações e consequências práticas. Seu desenvolvimento tende a ser bastante formalizado e objetiva a generalização, com vistas na construção de teorias e leis (Gil, 2008, p. 26)”.

Se classifica como uma pesquisa interpretativa participante, pois é uma "investigação que depende muito da definição e da redefinição dos pesquisadores sobre os significados daquilo que veem e ouvem” (Stake, 2011, p. 46). A pesquisa participante se caracteriza pelo "envolvimento dos pesquisadores e dos pesquisados no processo de pesquisa (Gil, 2008, p. $31)$ ".

Quanto a natureza do estudo, inscreve-se na metodologia qualitativa, pois esta trabalha com o "universo de significados, motivos, aspirações, crenças, valores e atitudes, o que corresponde a um espaço mais profundo das relações, dos 
processos e dos fenômenos que não podem ser reduzidos à operacionalização de variáveis (Minayo, 2001, p. 14)”.

Entre as estratégias qualitativas recomendadas por Creswell (2010), optou-se pelo estudo de caso, ou, como prefere Godoi, Bandeira-de-Mello e Silva (2006, p. 124) o estudo de caso interpretativo, pois, "além de conter uma rica descrição do fenômeno estudado, busca [...] desenvolver categorias conceituais que possibilitem ilustrar, confirmar ou opor-se a suposições teóricas".

Pereira et al. (2018, p. 65) informam que o estudo de caso "é uma descrição e análise, a mais detalhada possível, de algum caso que apresenta alguma particularidade que o torna especial". Além disso, de acordo com Yin (2005), em um estudo de caso, o pesquisador deve objetivar a vinculação de dados empíricos às questões iniciais do estudo de forma lógica, proporcionando fazer uma análise real. Yin (2005) complementa que o olhar descritivo permite observar e descrever os atributos de fenômenos específicos, no caso deste estudo uma rede de integração social.

Gil (2002) considera a coletada de dados por meio de um estudo caso, como uma das mais completas dentre os outros métodos, pois se ancora tanto em dados de pessoas quanto em dados documentais. Neste caso a observação direta foi utilizada para a coleta de dados subjetivos, a qual ajudou a compreender o comportamento dos sujeitos envolvidos na OSC.

Quanto aos objetivos, é de natureza explicativa e descritiva. Explicativa, pois teve como intuito oportunizar uma maior aproximação com o problema, de modo a levantar suposições partindo de levantamento bibliográfico e/ou entrevistas com pessoas que tiveram contato com as práticas do problema estudado, como enfatiza Gil (2002), este método pode ser classificado como estudo de caso, pois estimula a compreensão do pesquisador. É o tipo de pesquisa que mais aprofunda o conhecimento da realidade, porque explica a razão, o porquê das coisas (Gil, 2008). No campo da natureza descritiva, esta se aplica, pois, esta pesquisa é um estudo de caso (Triviños, 1987) e permite ao investigador um aprofundamento na busca de informações sobre o objeto pesquisado, descrevendo os fatos e fenômenos de uma determinada realidade e "vão além da simples identificação da existência de relações entre variáveis (Gil, 2008, p. 28)".

Por ser uma pesquisa qualitativa, como método valeu-se da observação participante, pois houve a imersão no dia a dia da OSC estudada, o que caracteriza o envolvimento dos pesquisadores durante a investigação, a qual possibilitou ter uma visão holística e natural da relação com as pessoas no ambiente estudado, observando a vida quotidiana (Fonseca, 2002) dos assistidos pela instituição, em que se estabeleceu um grau de envolvimento nas atividades.

Assim, durante o período de setembro de 2017 a dezembro de 2019, houve um acompanhamento (de um dos investigadores) no dia a dia da OSC, que atua com 14 unidades no Estado do Rio Grande do Sul, em que o objetivo principal é apoiar e amparar gratuitamente pessoas com diagnóstico de câncer e em situação de vulnerabilidade social. Neste estudo, será tratado sobre a unidade que atua na cidade de Ijuí /RS e abrange mais de 72 cidades da região.

\section{Referencial Teórico: uma Breve Explanação Sobre os Conceitos Norteadores deste Estudo - Gestão Social, Terceiro Setor e Desenvolvimento Humano}

A reflexão teórica está desdobrada em três itens, sendo o primeiro sobre o conceito de gestão social que traz os olhares de autores como Tenório, Allebrandt, França Filho, Cançado, Carvalho e da silva, na qual se percebe traços da teoria da ação comunicativa de Habermas, em que a gestão social está pautada em elementos da cidadania deliberativa que podem orientar o terceiro setor.

O segundo item trata sobre o conceito do terceiro setor, trazendo um breve histórico da criação das OSCs/Ongs, abordando a importância da sua atuação junto à sociedade; e, no que se refere ao conceito de desenvolvimento humano, este vem sob a ótica te ver o indivíduo para além do aspecto econômico, valorizando mais sua qualidade de vida, bem-estar e suas questões culturais. 


\subsection{Gestão social}

A gestão social vem de elementos da cidadania deliberativa e percebe-se que no ponto de vista da construção democrática, a gestão social "está envolta no entendimento na qual a sociedade torna-se protagonista nas relações com os demais segmentos", (Allebrandt 2012), tornando-se corresponsável como parte privilegiada neste processo de articulação de igualdade e empoderamento (Allebrandt, 2012a).

A emancipação do homem e de sua autonomia social é objetivada pela inserção na gestão social, tendo como possível saída o conceito de racionalidade comunicativa proposta por Habermas, que de acordo com Tenório (2008) é capaz de estabelecer elementos conceituais que contribuem para democratizar as relações sociais contemporâneas.

Neste caminho, a gestão social pode e deve ser usada como um instrumento de controle público sobre as políticas e os recursos investidos em ações, bem como pode ser usada como um instrumento que leva o empoderamento da sociedade através de processos de aprendizagem, acesso à informação, ações de capacitações relacionadas, delegação de agentes do território e as competências à gestão dessas políticas (Ribas, 2017).

Da Silva; Neto; Pacheco (2012) ancoram-se em importantes autores para um entendimento acerca do conceito de Gestão Social, trazendo diferentes enfoques que perpassam dimensões da política social (Silva, 2004), na qual a gestão social deve se ocupar da gestão de políticas sociais; entendida como ações de desenvolvimento local como um processo social (Bordin, 2009); e, amplia-se a discussão, ao destacar sua compreensão como a capacidade interventiva dos indivíduos e seu potencial transformador da sociedade, em que a dimensão social se torna um dos componentes essenciais da reprodução social (Dowbor, 1999).

O termo Gestão Social tem sido palco de grandes discussões, em que se trabalham interpretações variadas, mas que tem ganhado notoriedade no campo relacionado às discussões envolvendo o terceiro setor que chama atenção para o papel de organizações privadas atuando com objetivos públicos. Esse novo desenho coloca Estado e sociedade interligados no enfrentamento das problemáticas atuais, aonde a gestão das necessidades/demandas sociais, vem da própria sociedade, visando a coletividade, e são utilizados mecanismos de auto-organização, especialmente o fenômeno associativo (França Filho, 2003).

Ainda pode-se apontar que as principais características da gestão social, estão pautadas na tomada de decisão coletiva sem coerção, transparência, dialogicidade e entendimento (Cançado, Tenório e Pereira, 2011). A Gestão Social é um “[...] processo dialético, de organização social própria da esfera pública, fundado no interesse bem compreendido, e que tem por finalidade a emancipação do homem (Cançado, 2011, p.205) ". Aqui, percebe-se uma linha em que a Gestão Social, estaria mais ligada à Gestão Pública, no entanto, como ela ressalta a emancipação do homem/sujeito, é que se pode dizer que a Gestão Social, poderá nortear passos da gestão no Terceiro Setor (TS), que visa emancipar e empoderar as pessoas assistidas pelas ONGs/OSCs.

Contudo, se verifica que o tema Gestão Social tem sido evocado nos últimos anos para acentuar a importância das questões sociais para os sistemas de governo, sobretudo na instituição de políticas públicas (Cançado, 2012). O que vem a ser significativo para o TS, pois muitas instituições acabam favorecidas por algumas políticas públicas e emendas parlamentares.

Ainda neste contexto é importante ressaltar que

A gestão social é caracterizada por ser comandada pela razão comunicativa, pelo agir comunicativo; enfatiza a ação gerencial dialógica, participativa; o processo decisório é exercido por meio dos diferentes sujeitos sociais; baseada no entendimento mútuo entre os atores/sujeitos, na harmonização interna dos planos de ação pelos atores; exige a presença do discurso argumentativo sujeito as três pretensões de validade: veracidade, correção normativa e autenticidade, e a atuação dos atores com base na cidadania deliberativa (Cançado, 2012, p. 161). 
Outros elementos que compõem a Gestão Social, os mesmos extraídos da Cidadania Deliberativaa ${ }^{1}$; que são: a legitimidades nos processos de discussão, a inclusão, o pluralismo, igualdade participativa, autonomia e bem comum, podem nortear a gestão no terceiro setor, uma vez que, no caso das ONGs que apoiam/amparam pessoas em situação de vulnerabilidade social, e que estão em busca de seus direitos enquanto cidadãos, como exemplo; acesso à saúde, educação, cultura, laser, etc., ajudariam a elaborar projetos e políticas públicas que venham atender a demanda deste público.

Assim, as OSCs/ONGs, estão inseridas no que é chamado de Terceiro Setor e possuem características valorizadas na gestão social, que são:

[...] a capacidade de articular iniciativas múltiplas, revitalizando o envolvimento voluntário da comunidade ou de setores da sociedade civil; a capacidade de estabelecer parceria com o Estado na gestão de políticas e programas públicos; a capacidade de estabelecer redes locais, nacionais ou mundiais e, por meio delas, constituir fóruns de escuta e vocalização de demandas, introduzindo-as na agenda política (Carvalho, 2001, p. 16).

Desta forma, ao olhar pelo pensamento dos autores citados neste capítulo, é que se entende a possibilidade do Terceiro Setor, em ser norteado pela Gestão Social.

\subsection{Terceiro setor}

Como já mencionado anteriormente, as ONGs/OSCs, são instituições de caráter não governamental e que não visam a lucratividade, objetivando fazer a diferença no desenvolvimento social e econômico local, agindo com seriedade e comprometimento, na tentativa de minimizar as lacunas sociais, não atendidas pelos governos, em que seus atores sociais, acabam agindo como atores de transformação social.

Estas organizações compõem o que se denominou terceiro setor, sendo este, composto de entidades não estatais, sem fins lucrativos, que em parceria ou não com órgãos estatais e empresas privadas, prestam serviços de interesse público, através de trabalho voluntário ou assalariado ou através de associações (Pessoa, 2015).

No entanto, antes de aprofundar sobre o que é terceiro setor, é interessante termos uma noção do que são os outros dois setores.

Pessoa (2015) caracteriza o primeiro setor como um misto de ações/atividades do Estado, enquanto no segundo setor, estão as organizações privadas: empresas, indústrias, serviços, comércio, escolas, etc.

Assim, o primeiro setor se refere ao Estado, constituído de agentes de natureza pública, que trabalham com demandas com vistas a fins públicos (bens públicos), ao passo que o segundo setor é composto de agentes de natureza privada, que estabelecem atividades com propósitos privados (bens privados), pensando no mercado (Alves, 2002).

Já no que tange ao terceiro setor, Alves (2002), indica que este é integrado por agentes de natureza privada que executam planos/ações objetivando fins públicos. Esses agentes também podem ser voluntários que tenham afinidades pela causa.

Deste modo, o terceiro setor "estabelece uma consciência em relação à solidariedade e justiça social, possibilitando ao indivíduo o exercício pleno da cidadania, agregando valor substancial ao desenvolvimento da sociedade (Parceiros Voluntários, [2017], p.15)".

Cabe destacar que as instituições do terceiro setor, para que possam atuar com transparência, elas são devidamente constituídas e legalizadas, e para tanto, estão alicerçadas por algumas Leis e Decretos - Quadro 1.

1 Conceito que norteou a ideia de Gestão social. 
Quadro 1. Evolução das leis que fundamentaram o marco regulatório das OSCs.

\begin{tabular}{|c|c|}
\hline LEIS & DISPOSIÇÕES \\
\hline $\begin{array}{l}\text { Lei } n^{o} 9.637 \text { de } 15 \text { de } \\
\text { maio de } 1998 \text {. }\end{array}$ & $\begin{array}{l}\text { Dispõe sobre a qualificação de entidades como organizações sociais, a criação do Programa } \\
\text { Nacional de Publicização, a extinção dos órgãos e entidades que menciona e a absorção de suas } \\
\text { atividades por organizações sociais [...]. }\end{array}$ \\
\hline $\begin{array}{l}\text { Lei } n^{\circ} 9.790 \text { de } 23 \text { de } \\
\text { março de } 1999 .\end{array}$ & $\begin{array}{l}\text { Discorre sobre a qualificação de pessoas jurídicas de direito privado, sem fins lucrativos, como } \\
\text { Organizações da Sociedade Civil de Interesse Público, institui e disciplina o Termo de Parceria } \\
{[\ldots] \text {. }}\end{array}$ \\
\hline $\begin{array}{l}\text { Decreto Legislativo } \mathrm{n}^{\mathbf{0}} \\
3.100 \text { de } 23 \text { de março de } \\
1999 .\end{array}$ & $\begin{array}{l}\text { Regulamenta a Lei } n^{\circ} 9.790 \text {, e dispõem sobre a qualificação de pessoas jurídicas de direito } \\
\text { privado, sem fins lucrativos, como Organizações da Sociedade Civil de Interesse Público, institui e } \\
\text { disciplina o Termo de Parceria [...]. }\end{array}$ \\
\hline $\begin{array}{l}\text { Lei } n^{\circ} 12.101 \text { de } 27 \text { de } \\
\text { novembro de } 2009 .\end{array}$ & $\begin{array}{l}\text { Aborda sobre a certificação das entidades beneficentes de assistência social; regula os } \\
\text { procedimentos de isenção de contribuições para a seguridade social; altera a Lei no } 8.742 \text {, de } 7 \text { de } \\
\text { dezembro de } 1993 \text {; revoga dispositivos das Leis nos } 8.212 \text {, de } 24 \text { de julho de } 1991,9.429 \text {, de } 26 \text { de } \\
\text { dezembro de } 1996,9.732 \text {, de } 11 \text { de dezembro de } 1998,10.684 \text {, de } 30 \text { de maio de } 2003 \text {, e da } \\
\text { Medida Provisória no } 2.187-13 \text {, de } 24 \text { de agosto de } 2001 \text { [...]. }\end{array}$ \\
\hline $\begin{array}{l}\text { Lei } n^{\text {o }} 13.019 \text { de } 31 \text { de } \\
\text { julho de } 2014 \text {. }\end{array}$ & $\begin{array}{l}\text { Chamada de "novo marco regulatório", substituindo as Leis } 8.429 \text { e } 9.790 \text {, e estabelece o regime } \\
\text { jurídico das parcerias entre a administração pública e as organizações da sociedade civil, em } \\
\text { regime de mútua cooperação, para a consecução de finalidades de interesse público e recíproco, } \\
\text { mediante a execução de atividades ou de projetos previamente estabelecidos em planos de trabalho } \\
\text { inseridos em termos de colaboração, em termos de fomento ou em acordos de cooperação; define } \\
\text { diretrizes para a política de fomento, de colaboração e de cooperação com organizações da } \\
\text { sociedade civil; e altera as Leis } \text { n }^{\circ} \text { s } 8.429 \text {, de } 2 \text { de junho de } 1992 \text {, e } 9.790 \text {, de } 23 \text { de março de } 1999 \\
\text { [...]. }\end{array}$ \\
\hline
\end{tabular}

Fonte: (Ribas et al, 2020, p.12)

Com base no Quadro 1, é possível ver um pouco a evolução das Leis e decretos que amparam as organizações do terceiro setor, sendo que a mais significativa, é a que ficou marcada como Marco Regulatório das Organizações da Sociedade Civil - MROSC, ou simplesmente "novo marco regulatório" que veio com a implementação da Lei 13.019 de 31/07/2014 que entrou em vigor somente em 2016. Esta deu ênfase a uma nova denominação para as entidades sem fins lucrativos, que são as Organizações da Sociedade Civil - OSC, nomenclatura que está inclinada a substituir a denominação Organizações Não Governamentais $-\mathrm{ONG}^{2}$.

A partir da implementação do MROSC, além de aumentar a capacidade de atuação das OSCs, foi possível um diálogo mais intenso com os governos, pois o novo marco possibilita as parcerias entre o Estado e as OSCs, estimulando uma gestão pública democrática participativa entre todas as esferas governamentais, assegurando a efetivação dos direitos do cidadão.

Neste contexto, se verifica que organizações do terceiro setor - OTS, estão amparadas legalmente, o que garante que estas exerçam suas atividades de acordo com seus objetivos propostos. Estas instituições ainda são regidas por seus estatutos e plano de atividades, e também, inscritas nos respectivos conselhos ao qual pertencem, exemplo: Conselho Municipal do Idoso, Conselho Municipal de Desenvolvimento Social, etc.

No entanto, o TS, se for olhado no âmbito de suas ações, ele presta diversos serviços, como educação, saúde, laser, cultura, assistência social, etc., além de agir no campo da defesa na garantia dos direitos, na defesa do meio ambiente, na cooperação para o desenvolvimento e alguns casos, no monitoramento de políticas públicas (Carvalho, 1998). Com isto, esta autora afirma que o Terceiro Setor está entre o mercado e Estado "ora quase mercado, ora quase Estado".

2 Esta ideia se compôs, uma vez que OSC reflete melhor o trabalho/objetivos das instituições que são organizadas/formadas pela sociedade civil no intuito de atender as demandas/necessidades da sociedade (saúde, educação, assistência social, cultura, esporte, proteção de direitos da criança, adolescentes e idosos, proteção de animais e ao meio ambiente, etc.), enquanto ONG apenas informa que tais organizações têm fins sociais, mas não fazem parte do governo (Cazumbá, 2018). 
Ao analisar o TS por meio de seus arranjos e dinâmica, constata-se que neste meio, transitam instituições heterogêneas, voluntárias ou sem fins lucrativos, que vão desde associações comunitárias micro locais a organizações que atuam em redes estaduais e globais.

Cabral (2007 apud Cabral 2008) percebe as Organizações do Terceiro Setor - OTS, como sendo manifestações de espaços públicos, uma vez que sua composição e suas características legais se intitulam como uma nova opção para gerir formas de produção de bens públicos e reprodução dos valores sociais estimados, ao mesmo tempo em que articulam diferentes grupos de interesses coletivos, fundamental para a existência das OTS.

A mesma autora aponta que nas OTS é encontrada uma diferenciação de atores sociais, a qual apresenta categorizada em cinco grupos:

[...] instituidores, correspondendo ao grupo original que instalou a organização, manifestou sua missão e propiciou os recursos materiais e ideológicos iniciais; funcionários, correspondendo ao grupo de indivíduos que se vincularam legalmente como trabalhadores da organização e assumiram ao longo do tempo um determinado grau de identidade com os pressupostos da organização; voluntários, como um grupo relativamente transitório que se articula à organização de modo autônomo e realiza parcelas das tarefas, ou contribui com trabalho, participação ideológica ou empenho pessoal, não remunerado, com intensidade e características diversas; doadores, correspondente ao conjunto, nem sempre internamente articulado de indivíduos, que contribui financeiramente para a manutenção da organização; e, finalmente o público alvo, que constitui o grupo de beneficiários dos serviços prestados pela organização, ou seja, o cidadão portador de direitos, com capacidade de autonomia e liberdade para decidir sobre sua vida individual e coletiva - para quem se destinam as ações das OTS (Cabral, 2008, p. 06).

Estes atores sociais se reconhecem por diferentes valores, como expectativas, necessidades, capacidades, interesses e representações sociais da missão. Para esses valores a autora deu a nomenclatura de ENCIR (Cabral, 2008).

Assim, neste caminho, as OTS, promovem ações que vão ao encontro com elementos que regem a Gestão Social, a fim de proporcionar o apoio necessário ao público benificiário e ou assistido. Estas instituições "sustentam apelos solidários; promovem bens e serviços; têm uma missão social; executam uma política de inclusão pela ótica da universalidade; equilibram o requisito do controle social (pois desenvolvem uma missão autônoma) e são fidedignas perante a sociedade e aos beneficiários" (Cabral, 2004, apud Cabral 2008).

Em suma, as OTS são entidades que se tornaram protagonistas no campo social, sendo fundamental para a efetivação da cidadania, acarretando em uma significativa atuação na vida das pessoas, efetivando os interesses sociais, agindo em prol a coletividade, ampliado a solidariedade, motivando voluntários, e impactando positivamente na vida das pessoas, em que o foco principal é atender as demandas, melhorando a qualidade de vida, sem visar a lucratividade.

Neste contexto se constata ser necessário a interlocução e parcerias públicas com entidades e organizações que não visam lucro, pois isto tem gerado impactos positivos no desenvolvimento social e econômico local (Dutra et al, 2020).

\subsection{Desenvolvimento humano}

O termo Desenvolvimento Humano - DH, tratado neste trabalho, está voltado para o indivíduo, partindo dos pressupostos elencados pelo Programa das Nações Unidas para o Desenvolvimento - PNUD, que entende que se deve olhar para o sujeito, para além do aspecto econômico, indo para um pensamento voltado a qualidade de vida das pessoas, e nisto está incluso também as questões sociais, culturais e políticas que influenciam no bem-estar da vida humana. Estes elementos também são balizadores para da base do Índice de Desenvolvimento Humano - IDH³ e do Relatório de Desenvolvimento

3 Este índice compara indicadores de países avaliando os elementos de riqueza, alfabetização, educação, esperança de vida, natalidade e outros, com o intuito de avaliar o bem-estar de uma população. Varia de zero a um e é divulgado pelo Programa das Nações Unidas para o Desenvolvimento (Pnud) em seu relatório anual. Países com IDH até 0,499 são considerados de desenvolvimento humano baixo, e os com índices entre 0,50 e 0,799 são considerados de desenvolvimento humano médio e acima de 0,80 são considerados elevados (IPEA,2008). 


\section{Humano - $\mathrm{RDH}^{4}$ (PNUD, 2000).}

Nisto, entende-se que nesta ótica o DH busca ver o sujeito como protagonista de suas escolhas, para que tenham habilidade e oportunidades para ser o que almejam. Claro que o fator econômico é importante, mas este vem como um aspecto fim, e não como meio de desenvolvimento. O desenvolvimento humano tem a ver com as liberdades humanas. Trata-se de construir capacidades humanas, não apenas para alguns, nem mesmo para a maioria, mas para todos (PNUD, 2018).

Nota-se aqui um novo ponto de vista, em que o DH prioriza o crescimento humano, para além da sua capacidade de crescimento econômico ou de renda. Neste processo, se considera que o ideal é que haja um universo em que esteja sincronizado ao ambiente externo, “[...] para assim trazer segurança para as perdas e frustrações. Ampliar a liberdade das pessoas, dando o direito e a oportunidade para que todos possam escolher a vida que desejam ter (PNUD, 2000)".

Em um novo contexto, no relatório do PNUD (2018), eles trazem uma nova abordagem, apontando que seria necessário uma correlação entre direitos humanos e desenvolvimento humano, e declaram ser fundamental enriquecer vidas e proporcionar liberdades, bem-estar e dignidade aos sujeitos “[...] uma concepção adequada do desenvolvimento humano não pode ignorar a importância das liberdades políticas e das liberdades democráticas [...] a liberdade democrática e direitos civis podem ser extremamente importante para melhorar as capacidades das pessoas em situação de vulnerabilidade social" (PNUD, 2018, p. 20, tradução e interpretação própria dos investigadores).

Assim, combinar direitos humanos com desenvolvimento humano está diretamente ligado na perspectiva de poder indicar os deveres dos outros na sociedade para melhorar desenvolvimento humano dos indivíduos de uma forma ou de outra. E com a invocação de deveres vem uma série de preocupações relacionadas, como responsabilidade, culpabilidade e responsabilidade (PNUD, 2018, tradução e interpretação própria dos investigadores).

Assim, é possível relacionar que as instituições do terceiro setor, se amparadas pela gestão social, poderão atuar no desenvolvimento humano das pessoas atendidas por estas instituições, de modo a fazer o seu papel diante da sociedade.

Esta ideia de DH, vem ao encontro com o pensamento da psicologia refletido na OSC estudada, na qual se preza o empoderamento dos assistidos e seu desenvolvimento enquanto sujeito. Nesse caminho, prioriza a busca de recursos internos que visam fortalecer a existência do ser no meio externo, partindo do princípio que toda e qualquer pessoa possa evoluir, aprender, transformar, desenvolver sua realidade, respeitando os limites de cada um, uma vez que cada pessoa reage de forma diferente frente a sua realidade e problemas enfrentados.

Esta questão fica evidenciada, pois a OSC estudada, recebe pessoas que:

Em decorrência do câncer passam por um processo de fragilidade frente aos recursos internos para enfrentamento, devido ao medo do que pode acontecer motivado pela ansiedade. Assim, por meio das intervenções se busca fazer com que as pessoas encontrem esse fortalecimento interno e consigam enfrentar o tratamento [...] para cada pessoa é um recurso diferente, pois depende dos tipos de mecanismos de defesa, da história vivencial, apoio, resiliência (Mello, 2020).

Contudo, se observa que, em função do que se mencionou sobre DH, é que este provoca; ou pelo menos deveria, grandes transformações que proporcionam na melhoria da qualidade de vida a todos que buscam o crescimento pessoal, além de possibilitar um espaço de qualidade perpetuando-se em um sujeito que possa viver bem e feliz, diante de sua realidade (Maranho, 2019).

Com este resgate teórico se entende que estes conceitos tem o embasamento para cumprir com o objetivo geral deste

4 Este relatório é utilizado pelas Nações Unidas a fim de disseminar e aumentar a conscientização sobre o desenvolvimento humano em todo o mundo. É um documento intelectual, publicado anualmente, com temas plurais, de cunho internacional, bem como apresenta os cálculos do Índice de Desenvolvimento Humano (IDH) de países do mundo. Também contém elementos garantidos por uma resolução da Assembleia Geral das Nações Unidas (1990), em que o primeiro relatório externava o entendimento de que as pessoas são a verdadeira riqueza das nações, conceito que guiou todos os relatórios subsequentes (PNUD). 
trabalho, qual seja: analisar os impactos causados por uma OSC - que atua no estado do rio grande do Sul, apoiando e amparando gratuitamente, pessoas que estão em tratamento oncológico.

\section{Apresentação e Análise da OSC}

Este capítulo traz um pouco a trajetória da OSC estudada, com alguns dados a nível estadual, no entanto, será abordado mais profundamente sobre a unidade que atua no município de Ijuí/RS.

A instituição iniciou suas atividades em 2005 e atualmente conta com 14 unidades no estado do Rio Grande do Sul. Tem como objetivo atender/apoiar gratuitamente pessoas com diagnóstico de câncer e em situação de vulnerabilidade social, e seus familiares. As unidades estão instaladas nas cidades de Bagé, Bento Gonçalves, Camaquã, Caxias do Sul, Ijuí, Lagoa Vermelha, Lajeado, Passo Fundo, Pelotas, Porto Alegre, Rio Grande, Santa Cruz do Sul, Santa Maria e Uruguaiana, abrangendo assim, todo estado do Rio Grande do Sul.

É uma OSC, devidamente constituída/legalizada, regida por estatuto e mantida principalmente com recursos captados/advindos da sociedade.

A instituição tem como Visão ser um centro de referência em atendimento a pacientes com Câncer, por meio de ações decisivas para a consciência do tratamento e da prevenção e como Missão busca atender, orientar, integrar e fornecer assistência humano social bem como financeiro material às pessoas com câncer que se encontram em situação de vulnerabilidade social, a fim de proporcionar uma melhor qualidade de vida a estas pessoas. Seu Objetivo é fortalecer os usuários na defesa e garantia dos seus direitos, visando à superação da situação de vulnerabilidade social e pessoal, devido à doença oncológica e outras questões sociais, bem como proporcionar uma melhor qualidade de vida durante o tratamento.

A OSC tem como finalidade principal: coordenar, planejar, elaborar, assessorar, executar serviços, programas, projetos e benefícios socioassistenciais de forma gratuita, continuada, permanente e planejada, para indivíduos e famílias em situação de vulnerabilidade e risco social, devido à doença oncológica.

Frente à fragilidade socioeconômica e emocional que a doença provoca no usuário assistido e em toda a família, a instituição oferece acompanhamento com assistentes sociais e psicólogos, os quais acolhem, orientam e identificam as necessidades dos que procuram ajuda nas unidades, e por meio de campanhas junto à sociedade, buscam atender de forma integral todas as necessidades/demandas desta família, pensando em proporcionar uma melhor qualidade de vida e bem-estar dos mesmos.

São ofertados diversos serviços, como a Casa de Apoio para acolhimento provisório, com pernoite e quatro refeições diárias (café da manhã, almoço, lanche da tarde e jantar), atendimentos individuais, grupos de apoio, encontros, visitas domiciliares, oficinas, confraternizações e passeios.

Ainda, são pensadas ações que visem proporcionar aos atendidos, oficinas de geração de renda, para que tenham uma possibilidade de, após o termino do tratamento, ter uma garantia de subsistência, empoderando-os financeiramente.

A instituição oferece para toda a sociedade, palestras de promoção à saúde e, com temáticas voltadas a prevenção aos adoecimentos e o autocuidado, uma vez que, as pesquisas apontam que o câncer, se diagnosticado precocemente, aumenta em mais de $90 \%$ as chances de cura. Em termos estatísticos, o câncer é a doença crônica mais curável atualmente, sendo aproximadamente em 50\% dos casos na realidade dos países desenvolvidos. No Brasil, estes números são inferiores por causa da demora no diagnóstico (Oncoguia, 2017).

Esta última afirmação, aponta para a importância de se trabalhar a temática da prevenção, ilustrando que as palestras ofertadas pela OSC de forma gratuita para a sociedade são de suma importância e tem um valor imensurável, haja visto, que podem ajudar a salvar vidas.

Desde que iniciou seus trabalhos, a OSC a nível estadual, atendeu até dezembro de 2019 cerca de 19344 pessoas, 
sendo destes, 4.157 cadastros ativos (atendidos), ou seja, são pessoas que neste período estavam recebendo algum benefício da instituição. Estes trabalhos direcionados a estes usuários ativos, estão pautados no fortalecimento de vínculos entre pessoas com câncer e familiares, garantia e defesa de direitos e o abrigamento provisório e transitório durante o período de tratamento. Importante salientar que, em um levantamento realizado em todas as unidades, em 2019, houveram 251.856 atendimentos, envolvendo as pessoas com câncer, familiares, público atendidos nas palestras, entre outros.

No que se refere à unidade de Ijuí, esta possui mais de dois mil cadastros, sendo que destes, mais de 500 estão ativos (pessoas que recebem algum benefício da instituição). São realizados cerca de 40 a 50 novos cadastros por mês, e no ano de 2020 foram 5.590 atendimentos no Serviço de Acolhimento Provisório e 4.689 no Programa de Assessoramento Defesa e Garantia de Direitos.

Além da casa de apoio para colhimento provisório, a OSC, de acordo com a análise sócio econômica feita pela assistente social: oferta kit alimentação ${ }^{5}$ e suplemento ${ }^{6}$. Esta unidade conta com um espaço físico que atende 28 pessoas para pernoite, sala de convivência, refeitório, cozinha, banheiros, salas de acolhimento. Para atendimento aos usuários e seu acompanhante, conta com um quadro de funcionários, sendo um coordenador (que também atua na unidade de Santa Maria e Uruguaiana), duas assistentes sociais e um estagiário do serviço social, uma psicóloga, uma recepcionista, uma pessoa no administrativo, uma higienizadora, duas cuidadoras noturnas, uma assessora de comunicação, e seis mensageiros (que são responsáveis em buscar a doações recebidas na cidade de Ijuí e em mais de 72 municípios).

No que se refere às pessoas que não conseguem espaço para o pernoite, ou que vão até o município de Ijuí todos os dias para o tratamento e retornam às suas cidades, estes passam o dia na instituição, e participam de todas as atividades que são realizadas, bem como, recebem todas as refeições durante o tempo que ali permanecem.

Acerca da manutenção dos serviços, a instituição faz campanhas, via telemarketing, junto à sociedade, para a arrecadação dos recursos, uma vez, que não recebem verba de nenhuma esfera governamental. Ainda, são realizadas diversas ações com o intuito de captar recursos para que todos os usuários possam ser atendidos na integralidade. Projetos via editais, são escritos e submetidos, a fim de proporcionar benefícios aos usuários, como exemplo, o projeto de geração de renda, que visa oferecer cursos de doces e salgados e oficinas de artesanato no intuito de que eles possam, a partir disto, ter uma fonte de renda, além de ser um espaço de integração entre os usuários, seus familiares, voluntários e funcionários.

Para que a sociedade tenha conhecimento do trabalho realizado pela OSC, o setor de comunicação veicula campanhas de divulgação, contendo materiais institucionais, bem como, abordando temáticas de promoção à saúde, trabalhando datas especificas, como o Verão Laranja que fala sobre a prevenção ao câncer de pele; Julho Verde - cabeça e pescoço; Outubro Rosa e Novembro Azul que abordam sobre o câncer de mama e de próstata (as mais populares), entre outras. Os meios mais utilizados são as mídias sociais - Facebook e Instagram, um informativo que é trimestral distribuído em todo estado e entrevistas em rádios.

Percebeu-se que as equipes que atuam nesta esta OSC, não medem esforços para poder atender um número cada vez maior de pessoas, que diariamente procuram a instituição em busca deste apoio. Todas ações realizadas pela entidade, em prol de seus usuários; claramente se percebe, que impactam positivamente na vida destas pessoas, que se sentem mais fortalecidas para o enfretamento da doença.

\footnotetext{
${ }^{5}$ Espécie de cesta básica, montado com itens disponíveis na despensa, mas que geralmente contém arroz, feijão, farinha de trigo, farinha de milho, açúcar, óleo, etc. Esses itens são arrecadados em campanhas, por meio de projetos que a instituição chama de banco de alimentos, doação espontânea pela sociedade e/ou grupos e em supermercados.

${ }^{6} \mathrm{O}$ suplemento, normalmente é prescrito pela nutricionista, a fim de apoiar no tratamento, quando a pessoa estiver com baixa imunidade. É ofertado pelo estado, porém, deve ser encaminhado no município, sendo que este processo leva em torno de 30 a 60 dias. Nesse meio tempo, a instituição, por meio de campanhas via telemarketing, busca fornecer de forma gratuita até que o atendido receba pelo estado.
} 


\section{Atuação da OSC Frente a Pandemia: a Covid-19}

O ano de 2020 está marcado pela aparição de um vírus, a Covid- 19, que impactou o cenário mundial, gerando o caos global, provocando uma desordem social e econômica. Isso tudo devido à dimensão alcançada e à velocidade com que se disseminou, abalando profundamente a vida de todos, uma vez que nenhum país estava preparado para o enfrentamento desta pandemia.

Foram necessárias muitas medidas de proteção, e o isolamento social foi um dos principais critérios utilizados, aliados ao uso de máscara, álcool gel, e muita campanha educativa. No entanto, não foi o suficiente para frear a ação do vírus, que é altamente contagioso e se alastra com uma rapidez inacreditável. Com isto, muitas atividades, principalmente às voltadas ao ensino, foram paralisadas e/ou adaptadas para o formato on-line.

Todos os setores foram atingidos, e no que se refere às organizações no terceiro setor, as OSCs que atendem as populações mais vulneráveis, que já trabalham com recursos reduzidos e sempre buscando alternativas para captar recursos, agora com a pandemia, mais do que nunca, precisaram se reinventar para poder continuar ofertando apoio.

Para a OSC estudada, não foi diferente, e pensar em novas ações para superar a pandemia e continuar prestando auxílio, foi necessária.

De acordo com o relato da Assistente Social (C.D.M.) que atua na instituição, no período de pandemia, foi necessário readequar todos serviços da instituição, bem como acatar os novos protocolos do ministério do trabalho, e todos os critérios de prevenção.

Este ano para nós foi bem mais trabalhoso no sentido de se reorganizar e encontrar meios de dar continuidade ao trabalho, foi necessário readequar as dinâmicas de atendimento da instituição e mesmo diante deste cenário, não paramos os atendimentos, até porque nossos usuários continuam seus tratamentos, de modo que todos que chegaram até a instituição foram atendidos, dentro das suas necessidades. Buscamos estar mais próximos das secretarias da saúde e com o serviço social do CACON (entrevista com C.D.M.).

Sobre os serviços, de acordo com C.D.M, na questão da suplementação foi dado continuidade, "atendemos de forma normal, e em alguns momentos, com agendamentos, sempre tomando todos os cuidados, respeitando as normas de proteção e de distanciamento".

Acerca do acolhimento provisório na casa de apoio, houve a continuidade, mas infelizmente, de forma reduzida, deixando apenas um usuário e seu acompanhante por quarto, onde foram priorizadas as pessoas que moravam mais distantes do município.

Fizemos todos um planejamento para que pudéssemos atender nossos usuários de forma que eles não fossem expostos aos riscos, mas de modo que todas as necessidades deles fossem supridas, até porque, o tratamento oncológico não parou por conta da pandemia. Ações como, quando o usuário estava/está internado, ao invés de seu acompanhante vir até a instituição fazer suas refeições, nós levávamos a marmita até eles, até mesmo, usuários hospedados em outras pensões (as quais eles têm somente o pernoite), estes vinham na associação para buscar suas marmitas. Deste modo, conseguimos fazer os atendimentos, respeitando o isolamento social, além claro do uso de todos os protocolos, como a obrigatoriedade da máscara e o álcool em gel. Os usuários que estão na casa de apoio, foram orientados também a não circular pela cidade, fazendo apenas o percurso entre a casa de apoio e o hospital. Readequamos todos os atendimentos, mas não deixamos de atender (C.D.M.).

Acerca das outras ações, como arrecadação de alimentos, palestras de promoção a saúde, blitz, oficinas, capacitação e participação em eventos, estas também foram adaptadas para o formato on-line, e/ou, algumas infelizmente acabaram não ocorrendo, "[...] a arrecadação de alimentos e produtos de higiene e limpeza no mercado foi paralisada no início, mas depois retornamos com algumas adequações, e com o menor contato físico possível com as pessoas (C.D.M.) ”. 
No quesito captação de recursos, talvez este seja o de maior e importância e o que sofreu mais impacto inicialmente, pois diante de tantas incertezas e com receio do que viria pela frente, muitos contribuintes cancelaram suas doações, pois sentiram necessidades de fazer reservas para garantir eventuais gastos familiares.

No início da pandemia foi mais complicado porque as pessoas ficaram com certo receio do que viria pela frente [...] muitas pessoas deixaram de ser contribuintes, mas acabaram voltando depois, assim como, alguns deixaram de contribuir, mas em contrapartidas, outros vieram [...] mas passado um pouco o impacto inicial, outras pessoas acabaram percebendo a situação, de que o tratamento não poderia parar, e desta forma, nem nosso trabalho, e inúmeras pessoas procuraram a instituição para contribuir e ver quais eram as necessidades (C.D.M.).

Neste contexto, a instituição acabou trabalhando muito mais o marketing, usando muito as redes sociais e divulgando em rádios e jornais do município e da região, onde aproveitaram todas oportunidades que apareceram.

Além de todas as dificuldades enfrentadas, ainda foi necessário trabalhar com críticas "no início da pandemia recebemos muitas críticas de porquê estávamos trabalhando e enviando os mensageiros para buscar a contribuição, se havia uma pandemia veloz e se pedia o isolamento social (C.D.M.)". Foi necessário conscientizar a todos de que os tratamentos não pararam, de modo que a instituição também não poderia parar.

Então frente a todo este cenário, foi preciso muita resiliência, pois tivemos que nos adaptar as normas, buscar meios de captação de recursos, e ainda, explicar para a sociedade que nosso trabalho não poderia parar, pois nossos usuários precisavam do apoio da instituição, pois o tratamento de saúde deles não parou e por isso, não poderíamos parar. Como ficariam estas pessoas sem o apoio? Se não fosse por nós, para onde eles iriam? (C.D.M.).

Diante disto, foi trabalhado uma campanha intitulada "Não nos abandone", no intuito de passar para a sociedade de que este momento, mas do que nunca, precisavam do apoio de todos, uma vez que a instituição não recebe verba de nenhuma esfera governamental, sendo estes recursos a maioria advindos da colaboração da sociedade. Ainda tinha o objetivo de mostrar de que não tinha como parar os atendimentos, uma vez que as pessoas que estavam passando pelo enfrentamento do câncer, não poderiam parar com seus tratamentos.

Com isto, se percebe o quanto a OSC tem uma importância na vida de seus usuários, e que não mediram esforços para dar continuidade nos atendimentos.

\section{Resultados e Discussões}

Durante o período de envolvimento direto com a OSC, foram muitos os diálogos informais e atividades realizadas com os usuários dos serviços, tanto da pessoa que está em tratamento, como familiares, em que relataram o quanto foi importante o apoio recebido pela instituição:

\footnotetext{
"Aqui, eu encontrei todo o apoio que preciso"; "Quando cheguei, estava chateado por conta da doença, mas hoje, me sinto fortalecido e com muita esperança de cura"; "Não fosse este apoio, não sei como eu teria feito, pois sem dinheiro, não sei como faria para vir a Ijuí"; "Somos muito bem recebidos, por todos. Eu me sinto como se estivesse em casa"; "Sem o apoio da instituição, com certeza, meu tratamento seria comprometido"; "Eu e minha família, somos gratos por receber todo este apoio, pois sem isso, não sei como teríamos enfrentado toda essa situação"; "Fiquei assustado quando recebi o diagnóstico de câncer, achei que era o fim, mas quando passei a receber o apoio da entidade, eu vi que era um novo começo" (extraído de diálogos informais com os usuários e familiares).
}

Nesse período, foi possível perceber o quanto esta ajuda, tem sido fundamental na vida destas pessoas. Para os que ficam na Casa de Apoio durante o tratamento, à vivência com outras pessoas que estão passando pelo mesmo tratamento, faz com que percebam que esta não é uma realidade isolada, e que, são diversos os casos, de modo que um apoia o outro. Essa vivência mostra também, que para cada pessoa, o contexto é diferente, de modo, que nem sempre, o que acontece de uma 
forma para um, não necessariamente, será assim com o outro. Essa realidade é externalizada no depoimento de um dos usuários: "O apoio desta instituição foi fundamental na minha vida. Conheci lá a história de outras pessoas, o que me fez olhar para minha vida de uma forma diferente. Sou outra pessoa (J.F.B.F.) ${ }^{7 ”}$.

A OSC oferece diversas atividades com o objetivo de tirá-los do ambiente da doença, e com isto, realmente, a maioria relata que quando estão na Casa de Apoio, até esquecem que estão passando por este processo de adoecimento.

Ainda, médicos que atendem no CACON - Centro de Alta Complexidade em Oncologia apontaram para a equipe técnica da OSC, o quanto eles percebem em seus pacientes, a melhora durante o tratamento, para aqueles que recebem o amparo, pois se sentem mais seguros, refletindo de forma positiva, diretamente no bem-estar e na qualidade de vida destas pessoas, fazendo com que sigam de forma mais rigorosa todas as instruções de tratamento.

Essa constatação também pode ser percebida por parte dos atendidos pela instituição, que se sentem mais fortalecidos ao receberem o apoio, fundamental para a continuidade do tratamento:

“[...] conheci a instituição em 2018. Quando cheguei fui muito bem acolhido. O apoio que encontrei foi fundamental para eu continuar o tratamento do câncer com esperança (O.S.)". "Quando estamos na instituição pensamos em amor. Apesar do tratamento muitas vezes ser dolorido, é uma felicidade receber este apoio. Aqui, o desejo de lutar e seguir em frente aumenta (R.O.)". "A instituição faz parte da minha história. Desde que eu cheguei recebo carinho e apoio, como uma família. Isso tem me ajudado no tratamento contra o câncer de mama (E.S.)". "Esta instituição é a melhor coisa da minha vida, é minha segunda casa. Não sei o que seria de mim se não fosse este apoio enquanto enfrento o câncer de mama (I.B.M)".

Para alguns colaboradores, que visitaram pessoalmente a instituição, houve e menção de estarem muitos felizes, em ver que sua contribuição, faz tantas coisas, e percebem o quanto, tudo é tratado com carinho, cuidado e dedicação. Ainda, teve o relato de uma pessoa que contribui há algum tempo com a instituição, que; se ela, quando passou por isso na família, tivesse tido um apoio como este, com certeza, teria sido mais fácil à superação de enfrentar essa situação.

Assim, por meio deste estudo de caso, foi possível avaliar a importância do terceiro setor para o bem-estar das pessoas, e o quanto isto se torna significativo na vida delas.

Neste caso, em que se avaliou uma OSC que apoia pessoas em tratamento oncológico, se percebeu o impacto positivo na vida destas pessoas e seus familiares, pois o diagnóstico de câncer, ainda é percebido como uma "sentença de morte", e acaba afetando toda a rede familiar. E apoio como este, é fundamental para a continuidade do tratamento e na qualidade de vida da pessoa que está passando por ele, bem como, seus familiares. O Usuário E.G. reforça isso ao relatar que "O acolhimento e o atendimento da psicologia, da instituição como um todo, me deu muita força, desde que eu cheguei, após eu receber o diagnóstico do câncer de próstata. Com o apoio da associação o meu dia a dia passou a ser mais tranquilo (E.G.) ".

Muitos chegam até a instituição, fragilizados, com muitos "nãos", e aflitos, acabam não sabendo por qual caminho seguir, e ao serem atendidos de forma eficaz pela equipe técnica e por todos que fazem parte do quadro de funcionários, acabam percebendo que serão acolhidos, e terão apoio necessário enquanto estiverem fora de seus lares: “[...] recebi desta minha segunda família, atenção, carinho e apoio em um momento de muitas incertezas (R. C.)".

No entanto, em meio a tantas incertezas, mas com o apoio recebido, aos poucos vão ressignificando suas vidas. Muitos relatam que a doença foi um divisor de águas, separando a vida em antes e depois do câncer, o que acarretou no fortalecimento deles enquanto pessoas e enquanto família, e, em um túnel de esperança, acabam percebendo, que hoje em dia, com os novos avanços da medicina, o câncer tem muitas chances de cura, como podemos ver no depoimento de C.C.S. "Hoje estou curado, graças a Deus, mas não deixo de frequentar a instituição, pois aqui, recebi muito apoio [...]”. Esse relato também

7 No decorrer deste capítulo, aparecerão alguns depoimentos que foram extraídos do Informativo da Instituição (2020, out./nov./dez). Edição 36, ano 10, tiragem 145 mil. Foram utilizadas apenas as iniciais dos participantes a fim de preservar a identidade dos mesmos. 
aponta esse sentimento de amizade, de união, de família, de gratidão, que se constrói na instituição, pois acabam criando um elo entre os usuários e a associação, que movidos pela fé e pela esperança, e com o apoio recebido, acabam tendo uma melhor qualidade de vida durante o tratamento, atingindo assim os objetivos finais da OSC.

Assim, se percebe neste caso, que há muitos elementos que estão alinhados com o referencial teórico deste estudo, uma vez que vê claramente que estas pessoas são impactadas positivamente, com o apoio desta OSC, em que o principal objetivo é proporcionar a eles primeiramente um acolhimento que garanta o bem estar e a melhoria da qualidade de vida, de modo a dar-lhe novas chances de ver o mundo ao seu redor, e muitas vezes incentivar em mudanças de hábitos, que vem ao encontro com os cuidados da saúde, oferecendo novas oportunidades de ver seu modo de vida, além de, após isto, oferecer então, possibilidade de empoderar-se economicamente, a partir de oficinas que objetivam e fomentam a geração de renda.

Assim, neste caso, podemos ver que a gestão social no terceiro setor, se faz necessário, pois estão atuando diretamente com as pessoas, agindo e contribuindo para o desenvolvimento humano das mesmas, trabalhando inicialmente o que é mais importante: o "ser" da pessoa, oferendo um novo olhar, ressignificando a vida destes sujeitos, causando a emancipação do cidadão e de sua autonomia social.

Também se constatou que os autores que abordam sobre o terceiro setor, apontam que as OTS estão cada vez mais estruturadas e profissionalizas, e a associação analisada está dentro desta realidade, pois mantem em seu quadro de funcionários profissionais capacitados, que atuam dentro das normas, bem como, tem uma boa representatividade na equipe de comunicação. Ainda, estão sempre capacitando seus profissionais e voluntários.

Outro fator é que o trabalho realizado pela OSC, enfatizando a importância dos cuidados com a saúde, é que muitas situações podem ser evitadas, quando são socializadas informações de medidas de prevenção. E as palestras proporcionadas pela OSC (já mencionado anteriormente), fazem esse papel de alerta ao cidadão. Neste sentido, quanto mais alertar a população, menos ocorrerão situações como a do relato de M.L.R, que sempre trabalhou exposta ao sol: "desde nova trabalhei na lavoura, no sol, e sem o uso do protetor. Há anos me trato para o câncer de pele e, três vezes ao ano preciso realizar procedimentos, que consigo graças ao apoio da associação (M.L.R)". No entanto, novamente se enfatiza, a importância da OSC na vida destas pessoas.

Cabe ainda ressaltar, que todo o trabalho realizado pela OSC precisou ser remodelado frente ao momento mundial que estamos enfrentando, a Covid- 19; contexto este que impactou inicialmente os atendimentos, mas que logo foi contornado, mediante muito esforço por parte dos profissionais envolvidos, pois houve a necessidade de adequação na prestação dos serviços e atendimentos, moldando-se às normas impostas, mantendo o afastamento social, e isto tudo, de modo que os usuários pudessem ser atendidos em todas suas necessidades, uma vez, que o tratamento pelo qual estavam passando não tinha como parar.

\section{Considerações Finais}

Este estudo proporcionou aos pesquisadores, um aprofundamento nos conceitos da Gestão Social, Terceiro Setor, Desenvolvimento Humano, bem como, possibilitou um melhor entendimento neste cenário em que as OSCs estão atuando fortemente na Assistência Social e acolhimento provisório, pessoas que estão em vulnerabilidade social, carentes do saber, acerca de suas garantias de direito, no que tange à saúde, educação, cultura, laser, etc.

Foi possível perceber que o conceito de Gestão Social pode ser sim, norteador da gestão no terceiro setor, pois há muitos elementos que são praticáveis em ambos, com o exemplo, o pensamento no bem comum, na coletividade e no empoderamento ao sujeito.

Acerca do entendimento de Desenvolvimento Humano, foram encontrados elementos na OSC estudada que vão ao encontro com o entendimento de DH, como exemplo, a questão de olhar primeiramente o sujeito diante de suas aflições e 
vivência, e recolocando-os no centro de suas vidas.

De modo geral, se constatou que o apoio/amparo destas OTS, a seus assistidos, que elas produzem um forte impacto positivo na vida das pessoas, e, em muitos casos, colocam-nas de volta no eixo do convívio social, ao mesmo tempo em que as empoderam enquanto sujeitos.

$\mathrm{Na}$ OSC estudada, se observou nos atendidos uma melhoria na qualidade de vida durante o tratamento, atingindo assim os objetivos finais da OSC.

Contatou-se que as organizações sem fins lucrativos se firmaram como instituições que atuam fortemente na sociedade, amenizando demandas e emancipando pessoas, agindo em lacunas que o poder público não tem conseguido atender. Assim, estas instituições acabam por ter um importante papel diante da sociedade, pois trabalham sem ter como objetivo o lucro, e dependem de parcerias para a captação de recursos, seja com a sociedade civil, empresas e em raros casos, com o poder público.

Assim, se verifica que esta OSC tem uma atuação importante no campo do desenvolvimento social e econômico de seus usuários/atendidos, no entanto, com o cenário atual que estamos vivendo - Covid- 19, se constatou que a instituição sentiu a necessidade de se reinventar, principalmente na captação de recursos, pois a questão do isolamento social, mudou todo o cenário de arrecadação.

Ainda, foi observado de que, mesmo diante da pandemia, que a OSC, mesmo sofrendo os impactos causados pela Covid- 19, ainda assim, se remodelou e não deixou de prestar apoio aos seus assistidos, pois frente a tantas incertezas, o auxilio foi de extrema importância aos usuários dos serviços e seus familiares. O que só vem a corroborar com todas as colocações deste artigo, em que se enfatiza o importante papel das OTS, para o desenvolvimento social, humano e econômico das pessoas.

Por fim, este estudo, atingiu os objetivos propostos, no entanto, sugere-se ampliar para pesquisas futuras, aumentando a abrangência para as outras 13 unidades da Osc, que por sua vez, abrange todo o estado do Rio Grande do Sul, na qual se sugere a utilização de procedimentos metodológicos como entrevistas com questionário aberto, tendo como sujeitos os funcionários, voluntários, diretores, usuários e seus familiares, bem como, de análise documental a partir do estatuto que rege a associação, e/ou planos de trabalho.

\section{Agradecimentos}

Agradecemos à Capes/Prosuc (bolsa integral de doutorado) e ao CNPq (bolsa produtividade em pesquisa).

\section{Referências}

Allebrandt, S. L. (2012). Estado, administração pública e gestão social. In Siedenberg, D. R. (ORG.). Desenvolvimento sob Múltiplos Olhares. Ijuí: Unijuí, 139-186.

Allebrandt, S. L. (2012a). Espaços públicos e processos deliberativos: categorias e indicadores para monitoramento e análise. In: Bedin, G. A. (org). Cidadania, direitos humanos e equidade. Ijuí: Unijuí. 2012a, 153-195. Coleção direito, política e cidadania.

Alves, M. A. (2002, setembro). Terceiro Setor: as origens do conceito. Anais do XXVI Encontro da Associação Nacional de Programas de Pós-graduação em Administração (EnANPAD), Salvador, BA, Brasil.

Atlas Brasil. Atlas do Desenvolvimento Humano no Brasil. Disponível em: http://www.atlasbrasil.org.br/2013/pt/o_atlas/desenvolvimento_humano/.

Bordin, E. M. B (2009). A gestão social no contexto das organizaçães da sociedade civil: desafios para efetivação da Cidadania. 2009. 215f. Dissertação (Mestre). Curso de Serviço Social, PUC, Porto Alegre.

Carvalho, M. C. B. (2001, fevereiro). Introdução à Temática da Gestão Social. Revista Gestão de Projetos Sociais. Coleção Sociais Gestores Sociais. (3a ed.), $13-18$.

Carvalho, M. C. B. (1998) Sociedade Civil, Estado e Terceiro Setor. Revista São Paulo em Perspectiva, 12(4), 83 - 91.

Cabral, E. H. S (2008). A Gestão Social do Terceiro Setor e suas Dualidades. Revista Administração em Diálogo, 11(2), 21-34. 
Cabral, E. H. S (2007). Terceiro Setor: gestão e controle social. Saraiva.

Cançado, A. C (2012). Para uma análise da participação e da democracia: cidadania e desenvolvimento local: critérios de análise - elementos teóricos e empíricos. Revista Desenvolvimento em Questão, ano 10(21), 259-266.

Cançado, A. C. (2011). Fundamentos teóricos da gestão social. 246 f. Tese (Doutorado em Administração, área de concentração em gestão social, ambiente e desenvolvimento) - Universidade Federal de Lavras.

Cançado, A. C., Tenório, F. G., \& Pereira, J. R. (2011). Gestão social: reflexões teóricas e conceituais. Cadernos EBAPE.BR, 9(3), 681-703.

Cazumbá, N. (2018). Terceiro Setor: conceitos e responsabilidades. Curitba: Nossa Causa. E-book. https://nossacausa.com/ebook-conceitos-eresponsabilidades-no-terceiro-setor/.

Chaplin, R. L. (2017, Janeiro). O Estado, o terceiro setor e o mercado: uma tríade complexa. https://silo.tips/download/o-estado-o-terceiro-setor-e-o-mercadouma-triade-complexa-3.

Costa, A. L., \& Rosa, S. T (2003). Análise comparativa da eficiência e eficácia de gestão entre organizações do terceiro setor e organizações governamentais: um estudo de casos múltiplos nos serviços de educação infantil. Anais do XXVII Encontro da Associação Nacional de Programas de Pós-graduação em Administração (EnANPAD), Atibaia, SP, Brasil.

Creswell, J. W. (2010). Projeto de pesquisa: métodos qualitativo, quantitativo e misto. (3a ed.), Artmed.

Da Silva, K. V., Neto, L. M., Pacheco, A. S. V. (2012), A gestão social como alternativa gerencial em organizações do terceiro setor: um estudo de caso. Atos do Congresso Responsabilidade e Reciprocidade, 1(1), 172-180.

Dowbor, L (1999). Gestão social e transformação da sociedade. Novembro, 1999. <http:// http://dowbor.org/8_gestaosocial.asp>.

Dutra, P. H., Santos, C. M., Dias, C. A., \& Higuchi, A. K (2020). A estratégia de desenvolvimento local pela atuação em rede do poder público com as organizações da sociedade civil: uma revisão integrativa. Research, Society and Development, 9(6), e120962681. 10.33448/rsd-v9i6.2681. https://rsdjournal.org/index.php/rsd/article/view/2681.

Fernandes, R.C (1997). O que é o Terceiro Setor? Paz e terra.

Fernandes, R. C. (1994). Privado Porém Público: O terceiro Setor na América Latina. (2a ed.), Relume - Dumaré.

França Filho, G. C. (2003, junho). Gestão Social: Um Conceito em Construção. In: IX Colóquio Internacional Sobre Poder Local - II Colóquio Internacional El Análisis De Las Organizaciones Y La Gestión Estratégica: Perspectivas Latinas. Salvador, BA, Brasil.

Fonseca, J. J. S (2002). Metodologia da pesquisa científica. Apostila.

Gil, A.C (2008). Métodos e Técnicas de Pesquisa Social.

Gil, A. C. Como elaborar projetos de pesquisas. Atlas.

Godoi, C. K., Bandeira-de-Mello, R., \& Silva, A. B. de. (Orgs.) (2006). Pesquisa qualitativa em estudos organizacionais: paradigmas, estratégias e métodos. São Paulo: Saraiva.

IPEA. Mapa das Organizações da Sociedade Civil. https://mapaosc.ipea.gov.br/.

IPEA (2008). Desafios do desenvolvimento. https://www.ipea.gov.br/desafios/index.php?option=com_content\&view=article\&id=2144:catid=28\&Itemid=23.

Levitt, T. (1973). Third sector - nem tacties for a responsive society. Havard University, EUA.

Maranho, N. A. (2019, junho). Desenvolvimento Humano: Conceito na Psicanálise. Psicanálise Clínica. Com. https://www.psicanaliseclinica.com/desenvolvimento-humano/.

Mello, T. (2020, fevereiro). A Psicologia no Desenvolvimento Humano para as pessoas que estão em tratamento oncológico. Entrevista concedida aos autores para a elaboração deste artigo. Ijuí, RS, Brasil.

Minayo, M. C. S. (Org.), (2001). Pesquisa social: teoria, método e criatividade. Vozes.

Oncoguia (2017). Câncer tem cura? http://www.oncoguia.org.br/conteudo/cancer-tem-cura/81/1/.

Parceiros Voluntários (2017). Gestão sustentável e o marco regulatório das organizações da sociedade civil: o que precisamos saber sobre o MROSC.

Pereira, A. S., Shitsuka, D. M., Parreira, F. J., \& Shitsuka, R. (2018). Metodologia da pesquisa científica. UFSM, NTE. https://repositorio.ufsm.br/bitstream/handle/1/15824/Lic_Computacao_Metodologia-Pesquisa-Cientifica.pdf?sequence=1.

Pessoa, M. R. (2015). Regulamentação Jurídica do Terceiro Setor. Trabalho de Conclusão de Curso (Bacharelado em Direito) - Claretiano Faculdade, Rio Claro.

PNUD (2018). Human Development Indices and Indicators. https:/www.br.undp.org/content/brazil/pt/home/library/idh/relatorios-de-desenvolvimentohumano/relatorio-do-desenvolvimento-humano-2018.html.

PNUD (2000). Programa das Nações Unidas para o Desenvolvimento. https://www.br.undp.org/content/brazil/pt/home/idh0/conceitos/o-que-edesenvolvimento-humano.html. 
Research, Society and Development, v. 10, n. 1, e48610111918, 2021

(CC BY 4.0) | ISSN 2525-3409 | DOI: http://dx.doi.org/10.33448/rsd-v10i1.11918

Ribas, T. A. M., Metogbe, M., Allebrandt, S. L., Brum, A. L., Brizolla, M. M. B., Fistarol, R. K., \& Maroski, K. M. (2020, dezembro). Dinâmicas das organizações em rede no terceiro setor na perspectiva dos atores sociais que atuam em uma rede social no município de Ijuí - Rio Grande do Sul/Brasil. Research, Society and Development, 9(12), e29391211053. 10.33448/rsd-v9i12.11053. https://rsdjournal.org/index.php/rsd/article/view/11053.

Ribas, T. A. M. (2017). Controle social do desenvolvimento regional à luz da gestão social no âmbito do Corede Missões. Ijuí. 168f. Dissertação (Mestrado em Desenvolvimento) - Universidade Regional do Noroeste do Estado do Rio Grande do Sul, Unijuí, Ijuí.

Santos, C. C. dos, Dias, D. R., Domingues, H., \& Cotta, D. M (2019). Planejamento estratégico em Organizações Não Governamentais: o caso da Atlimarjom. Research, Society and Development, 8(5), e3985761, 2019. 10.33448/rsd-v8i5.761. https://rsdjournal.org/index.php/rsd/article/view/761.

Silva, A. A. da (2004). A gestão da seguridade social brasileira: entre a política pública e o mercado. Cortez.

Stake, R. E. (2011). Pesquisa qualitativa: estudando como as coisas funcionam. Penso.

Tenório, G. F. (2008). Um espectro ronda o terceiro setor: o espectro do mercado. Unijuí.

Tenório, G. F. (1998). Gestão social: uma perspectiva conceitual. Revista de Administração Pública. 32(5):7-23.

Triviños, A. N. S (1987). Introdução à pesquisa em ciências sociais: a pesquisa qualitativa em educação. Atlas.

Yin, R. K (2005). Estudo de Caso: planejamento e métodos. Bookman. 